\title{
Elaboration of $\mathrm{TiO}_{2}$ Ultrafiltration Membrane Deposited on Moroccan Sahara Clay
}

\author{
Mohamed Ait Baih ${ }^{1}$, Nour Elyakin El Qacemi ${ }^{1}$ Hamid Zidouh $^{1}$, Abdelhamid Bakka ${ }^{1}$, \\ Noureddine El Baraka ${ }^{1}$, Rachid Mamouni ${ }^{1}$, Nabil Saffaj ${ }^{1 *}$ \\ ${ }^{1}$ Laboratory of Biotechnology, Materials and Environment University Ibn Zohr, Agadir, Morocco
}

\begin{abstract}
In this work, the porous ceramic multilayer ultrafiltration membrane is developed. Macroporous support was formed by extrusion of ceramic paste derived from natural Moroccan Sahara Clay. The microporous interlayer was then performed by slip casting from zirconia commercial powders and finally the active ultrafiltration toplayer was obtained by solgel route using $\mathrm{TiO}_{2}$ sol. The performance of $\mathrm{TiO}_{2}$ ultrafiltration membrane was evaluated by pores diameter, thickness of the top layer, water flux, and molecular weight cut off (MWCO). The water permeability measured for this composite membrane is $9.051 \mathrm{l} /\left(\mathrm{m}^{2} \cdot \mathrm{h} \cdot \mathrm{bar}\right)$, the thickness is around $900 \mathrm{~nm}$, the pore diameter is centered near $7 \mathrm{~nm}$ and the MWCO was about 5000Da.
\end{abstract}

\section{Introduction}

Membranes have occupied an important position in chemical technology and is widely used. The key properties are exploited is the ability of membrane to control the permeation rate of a chemicals species through the membrane. The most popular example of the use of membranes is wastewater treatment to produce drinking water. Water is the main demand on the earth, because without water, life is impossible [1-2]. Conventional treatment of industrial wastewater needs different techniques such as precipitation of metallic cations, decantation, filtration and solvent extraction to remove the polluting agents [1].

Tangential filtration processes appear to be one of the most important advancements for liquid depollution processes due to their advantage compared to other modules like minimum membrane fouling thanks to high feed flowrate [2]. This is why membranes processes are now widely used in water industries for desalination (reverse osmosis), water purification (ultra and nanofiltration) and wastewater treatment by biomembrane reactors. The use of organic membrane is actually more developed but inorganic membranes display a number of performances advantages, such as better thermal, chemical resistance and mechanical strength [1-2].

Due to its high thermal resistance, excellent mechanical and chemical stability, and most importantly, high permeability and selectivity as performance parameters, many researchers have begun to show interest in new ceramic materials in the field of separation process.

* Corresponding author: saffaj@gmail.com 
Ceramics now include household, industrial and construction products, as well as various ceramic artworks, and are in a strong position in the competition with polymer membranes [2-4]. New ceramic materials for advanced ceramic engineering have been developed, such as structural ceramics, electrical and electronic ceramics, ceramic coatings and chemical processing, and environmental ceramics. [2]

Ceramic membranes can be obtained using asymmetric multilayer configuration where the different layers are coated on a macroporous support which offers a sufficient mechanical resistance. The cost of precursors, such $\alpha-\mathrm{Al}_{2} \mathrm{O}_{3}, \gamma-\mathrm{Al}_{2} \mathrm{O}_{3}, \mathrm{SiO}_{2}$, used in ceramic processing is significantly high and therefore contribute to the operating cost of membrane modules for industrial purposes [2-7].

To overcome the issue of the membrane cost, in this work, an asymmetric ceramic ultrafiltration multilayer membrane was elaborate. The first part consists to elaborate a new membrane support using natural abundant clay from south of Morocco (Laayoune, Sahara). The steps of elaboration of tubular ceramic membrane will be described. The formation of microporous interlayer from zirconia " $8 \mathrm{~m}^{2}$ " and formation of a thin ultrafiltration separation toplayer from $\mathrm{TiO}_{2}$ sol will be described.

The final part deals with a systematic investigation on the influence of membrane charge on the salt retention behavior. A series of $\mathrm{pH}$ dependent filtration experiments is carried out with $\mathrm{NaCl}, \mathrm{Na}_{2} \mathrm{SO}_{4}, \mathrm{CaCl}_{2}$ and $\mathrm{CaSO}_{4}$.

\section{Experimental}

\subsection{Membrane preparation}

\subsubsection{Preparation of the ceramic clay support}

Before preparing the ceramic paste, the natural clay was crushed and sieved through $160 \mu \mathrm{m}$ sieve. This powder will be blended with organic additives (Table 1), completely mixed dry to reach a uniform distribution of all components. This mixture in the presence of water enables us to achieve an agglomeration of grains of the desired paste properties (Fig. 1).

After mixing the components composing the ceramic paste, the obtained paste was stocked for at least 75 hours in a closed box under high humidity (aging time) to achieve greater consistency and to avoid the formation of air bubbles. The paste was then extruded to form a tubular support. The extruded pieces were dried at ambient temperature for 24 hours and transferred in an oven at $50^{\circ} \mathrm{C}$ for 24 hours.

Finally, a thermal treatment was carried out in a programmable furnace at $950^{\circ} \mathrm{C}$ for 2 hours. [8-11]. 


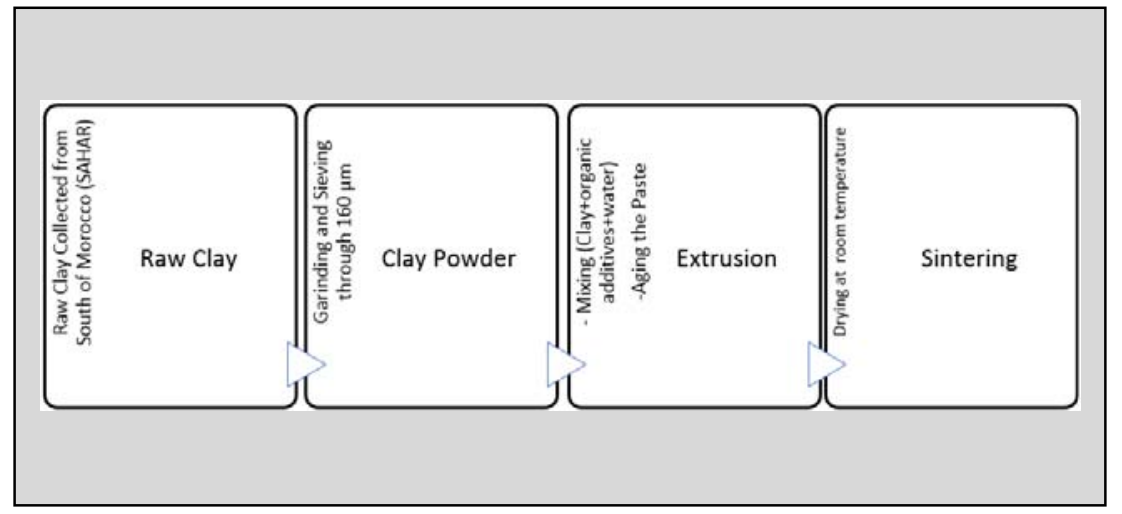

Fig. 1. Diagram showing the process used for support membrane elaboration.

Table 1. Percentage of each compound in relation to the total mass of powder.

\begin{tabular}{|c|c|c|}
\hline Product & Function & Quantity (\% mass) \\
\hline Clay & Ceramic Powder & 99.44 \\
\hline Amidon & Binder and Pore-Former & 0.56 \\
\hline Glycerin & Plasticizer & $0.55^{\mathrm{M}}$ \\
\hline Water & Solvent & $24.86^{\mathrm{M}}$ \\
\hline Zusoplast 126/3 & Lubricant & $0.26^{\mathrm{M}}$ \\
\hline
\end{tabular}

${ }^{\mathrm{M}}$ The percentage of each liquid compound is calculated relative to the total mass of powder.

\subsubsection{Preparation of zirconia membrane interlayer}

The powder suspension technique was used to prepare the zirconia microfiltration layer. A deflocculated suspension of zirconia was obtained by mixing $10 \mathrm{wt} \%$ of zirconia (Cezus Chimie) powder, $36 \mathrm{wt}^{*} \%$ of PVA (12 wt.\% aqueous solution) as binder and $54 \mathrm{wt} \cdot \%$ of Dolapix CE64 as dispersing agent (0.2 wt•\% aqueous solution).[12,13]

The zirconia layer was deposited on the inner surface of the clay support by slip casting. After drying at room temperature, the $\mathrm{ZrO}_{2}$ membrane was sintered at $900^{\circ} \mathrm{C}$ for $2 \mathrm{~h}$, after bonding at $300^{\circ} \mathrm{C}$ for $1 \mathrm{~h}$.

\subsubsection{Preparation of the $\mathrm{TiO}_{2}$ membrane top layer}

The ultrafiltration layer was prepared using sol gel route [13-14]:

a- $\mathrm{TiO}_{2}$ sol is prepared from the hydrolysis of $35.2 \mathrm{~g}$ of $\mathrm{Ti}(\mathrm{iOPr})_{4}$ by $111.6 \mathrm{~g}$ of water. After stirring for one hour, $65.2 \mathrm{~g}$ of a nitric acid solution 1 mol. $\mathrm{l}^{-1}$ is added. The solution is stirred and heated at $60^{\circ} \mathrm{C}$ for 24 hours to obtain the peptization. The sol is sieved at $125 \mu \mathrm{m}$ and diluted to $250 \mathrm{ml}$.

b- The sol $\mathrm{TiO}_{2}$ mixed with $10 \mathrm{~g}$ of hydroxyethyl cellulose ( $2 \mathrm{wt} \cdot \%$ aqueous solution) as binder.

c- Ultrafiltration layer preparation: the former sol was deposited in the inner part of the clay tubular support by slip casting. The coating time was 2 hours. The coated support was then dried for $24 \mathrm{~h}$ at room temperature, then sintered at $400^{\circ} \mathrm{C}$ for $2 \mathrm{~h}$, after bonding at $250^{\circ} \mathrm{C}$ for $2 \mathrm{~h}$. 


\subsection{Membrane characterization}

\subsubsection{Structural characterization}

The support and the ultrafiltration membrane were characterized by means of different techniques. The pore size of bulk support and intermediate layer were examined by Hgporosimetry (Micromeritics Autopore II 9215). For the top layer the pore size distribution was determined by nitrogen sorption (Micromeritics Asap 2010). The pore diameter was calculated by BJH method. The morphology, surface quality and thickness of intermediate and top layer membrane were examined by scanning electron microscopy (Hitachi, S-4500).

\subsubsection{Filtration tests}

The tangential filtration test was carried out on a laboratory-scale filtration plant, using a recycling configuration. It was equipped with a thermostated feed tank, an adjustable outflow pump, and a vertical membrane (length $15 \mathrm{~cm}$ ) module. The transmembrane pressure (TMP) was regulated by pressure valve and was controlled by two monitored pressure transducers located upstream and downstream the membrane module.

\section{A - Water permeability}

Ultrafiltration membrane (filtration area $19.6 \mathrm{~cm}^{2}$ ) was first characterized by their water permeability. Deionized water $(15 \mathrm{M} \Omega \cdot \mathrm{m})$ filtration was performed under increasing transmembrane pressure in the range of $2-10$ bars. The temperature was set to $25^{\circ} \mathrm{C}$ and a flow rate to $2.5 \mathrm{~m} \cdot \mathrm{s}^{-1}$. The water fluxes through the membrane were measured as a function of time at different transmembrane pressure values. Before these measurements, the membrane was conditioned by immersion in pure deionized water for a minimum of $24 \mathrm{~h}$.

\section{B - Retention for uncharged solutes-molecular weight cut-off (MWCO)}

The retention for uncharged components was studied by filtration experiments using polyethylene glycol (PEG, Fluka) with molecular weight from 600 to 5000. Feed and filtrate streams were analysed for their PEG concentrations by gel permeation chromatography (GPC, Waters Associates Chromatography) in order to obtain molecular weight distribution curves. Based on these curves, determine the retention percentage as a function of molecular weight. The molecular weight of the PEGs retained for $90 \%$ is taken as the MWCO of the membrane.

\subsubsection{Salts retention}

Salt retention was investigated by using four different salts: $\mathrm{NaCl}, \mathrm{CaCl}_{2}, \mathrm{Na}_{2} \mathrm{SO}_{4}$ and $\mathrm{CaSO}_{4}$ (Merck products). Salt retention was determined at different $\mathrm{pH}$ and concentration; the $\mathrm{pH}$ was adjusted by adding $\mathrm{HNO}_{3}$ for acidification and $\mathrm{NaOH}$ for alkalisation.

The percent salt retention was determined by comparing samples of feed and permeate solutions. These samples were analysed for their salts concentration by Chromatography ionic (Dionex Chromatography DX 100). All experiments were performed under a fixed working pressure of $10 \mathrm{bar}$. 
From the results, the percent retention was calculated with

$$
R(\%)=\left(1-C_{p} / C_{f}\right) * 100
$$

Where $C_{p}$ and $C_{f}$ are the salt concentration in the permeate and feed solution, respectively.

\section{Results and discussion}

\subsection{Properties of the composite membrane}

\subsubsection{Preparation of the ceramic clay support}

Performance of ceramic support membrane is governed by its morphology, which depends on the physical, chemical, and thermal properties of pore-former. Porous texture in the ceramic is controlled by Pore-Formers that, under sintering temperature conditions, release Carbone dioxide gas. The path taken by the released $\mathrm{CO}_{2}$ has thereby creates the porous texture of support and contributes to support membrane porosity [2-3].

On the basis of specified functions, additives are categorized as solvents (liquids), Binders, plastizers, and lubricants. Organic additives play an important role in ceramic forming. It's can be decomposed completely from the green body, thus reducing degradation of the final products [2-3].

Solvents are mainly used to provide fluidity of the powder during mixing and forming, and they can be used as dissolving agents for the powders.

Dispersants are used to stabilize suspensions of solid particles in liquid systems against flocculation and are sometimes considered to be defloculants. Dispersant can enhance the particle concentration for some usable viscosity of the slurry.

During the formation of ceramics, a binder is used in the raw material mixture to provide strength to the ceramic body by forming bridges between particles. Binder can provide plasticity of the feed materials for supporting the ceramic manufacturing.

Plastizers are lower molecular weight organic substance used to soften the binder in the dry state, thus increasing the flexibility of ceramic body.

Lubricants are used to reduce the function between particles themselves and between the particles and die wall in extrusion molding.

For the elaboration of a support membrane, the pore size, the porosity, and mechanical strength are the key factors which should be considered. The support prepared from Moroccan Sahara clay shows a porosity of ca. $44 \%$, pore size of ca. $5.14 \mu \mathrm{m}$ and mechanical strength of ca. $12 \mathrm{MPa}$. (Fig.2) 


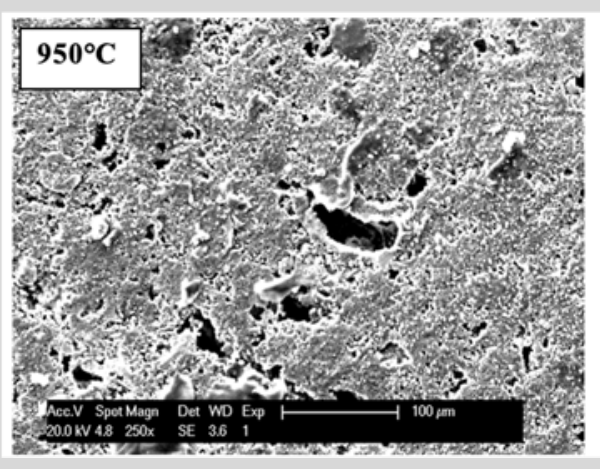

Fig. 2. Scanning electron micrographs of ceramic membrane support.

Microfiltration membranes have a large range of pores, which causes transportation of solvent through the pores by convection. This can be easily described by the Hagen-Poiseuille equation, if the nature of the pores is assumed to be cylindrical. Microfiltration membranes are generally prepared as a film supported over a macroporous ceramic support, which gives excellent mechanical strength, but offers negligible gas transfer resistance during separation of gas. Sometimes, an intermediate film is introduced between the ceramic support and the top separation film to reduce the opening between large pores of the support and the small pores of the top separation film. MF ceramic membranes possess two different types of pore structures: tortuous and capillary pores. The tortuous porous membrane provides a spongelike structure, high surface area, long life and high dust load. The capillary membrane provides a cylindrical structure with a well-defined pore size and pore structure.

The elaborated support was first coated by zirconia using slip casting process. The Elaborated zirconia layer constitutes an intermediate layer.

After sintering at $900^{\circ} \mathrm{C}$ for $2 \mathrm{~h}$, the zirconia layer presents a pore diameter of $0.25 \mu \mathrm{m}$ and an average thickness of the layer above $12 \pm 4.5 \mu \mathrm{m}$ (fig.3).

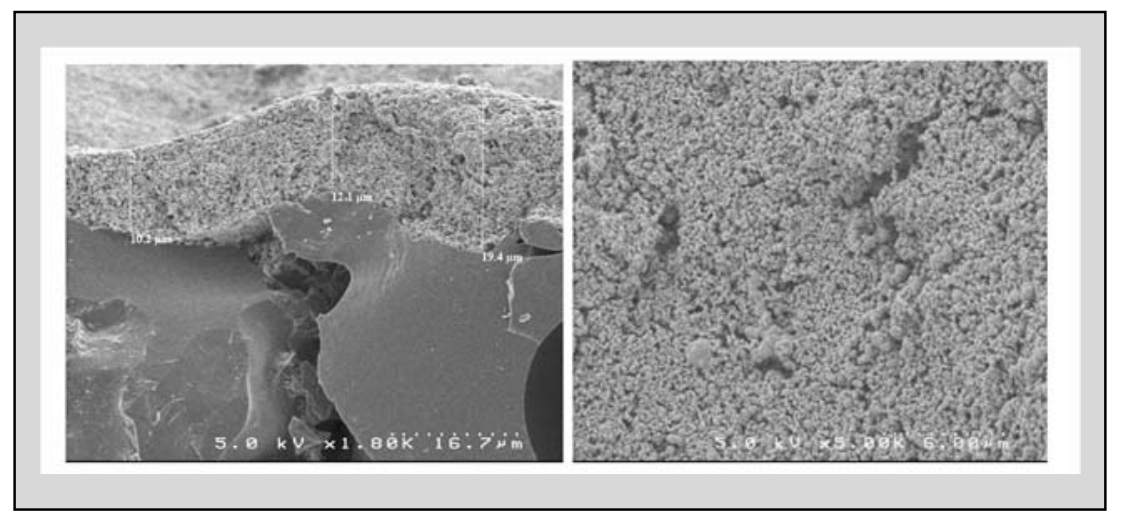

Fig. 3. Scanning electron micrographs of zirconia interlayer. 
UF membranes have been prepared from a wide range of polymer materials as well as ceramic materials. The growth of ceramic membrane for UF application compared to polymeric one sis mainly due to high thermal, chemical, and mechanical resistivity.

The final $\mathrm{TiO}_{2}$ ultrafiltration layers obtained by sol gel process presents a pore diameter centered on $7 \mathrm{~nm}$. In Fig. 4, the SEM micrograph of $\mathrm{TiO}_{2}$ layers, the thickness homogeneity can be observed. The thickness is around $900 \mathrm{~nm}$.

The resulting microstructure and the pore size distribution of the layers, which are particularly important for potential ultrafiltration applications, can be adjusted. They depend on a wide range of parameters such as, the particle size of the sol, the kind and quantity of the binder, the drying and sintering regime.

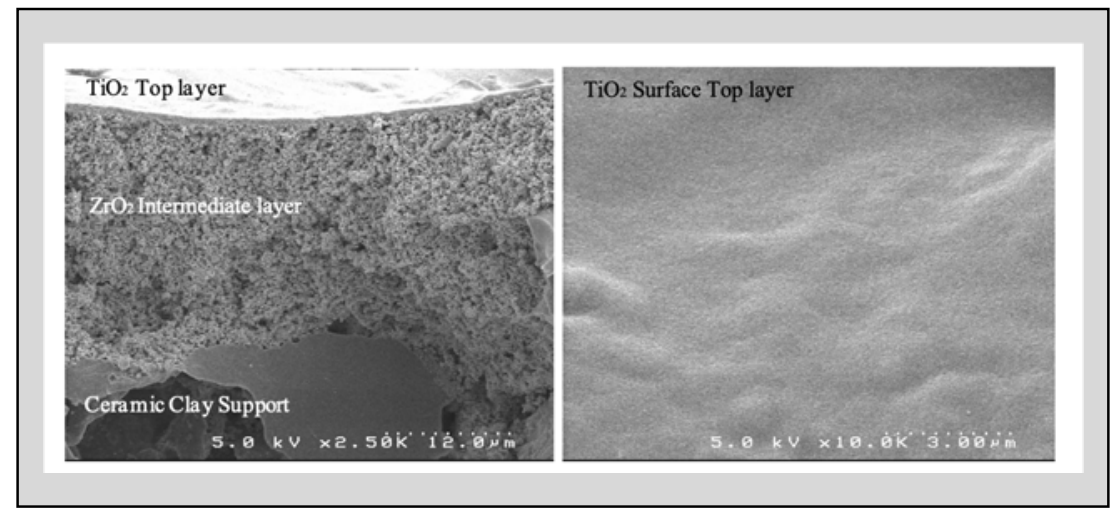

Fig. 4. Scanning electron micrographs of $\mathrm{TiO}_{2}$ membrane

\subsection{Filtration results}

Ultrafiltration (UF) is a pressure-driven membrane separation process where porous membranes are used to separate relatively large molecules from smaller ones or a colloidal suspension. The mechanism for separation of the solvent from the solute is called sieving or size exclusion. A sieving mechanism is a process by which the rejection of solute is determined based on the pore size and pore size distribution of the ceramic membranes.

\subsubsection{Water permeability}

Ultrafiltration membrane was first characterized by their water permeability. Fig.5 shows the water flux through the membrane depends on the applied pressure. The water flux increases linearly with pressure and permeability is on average $9.05 \mathrm{l} / \mathrm{h} \cdot \mathrm{m}^{2} \cdot$ bar. 


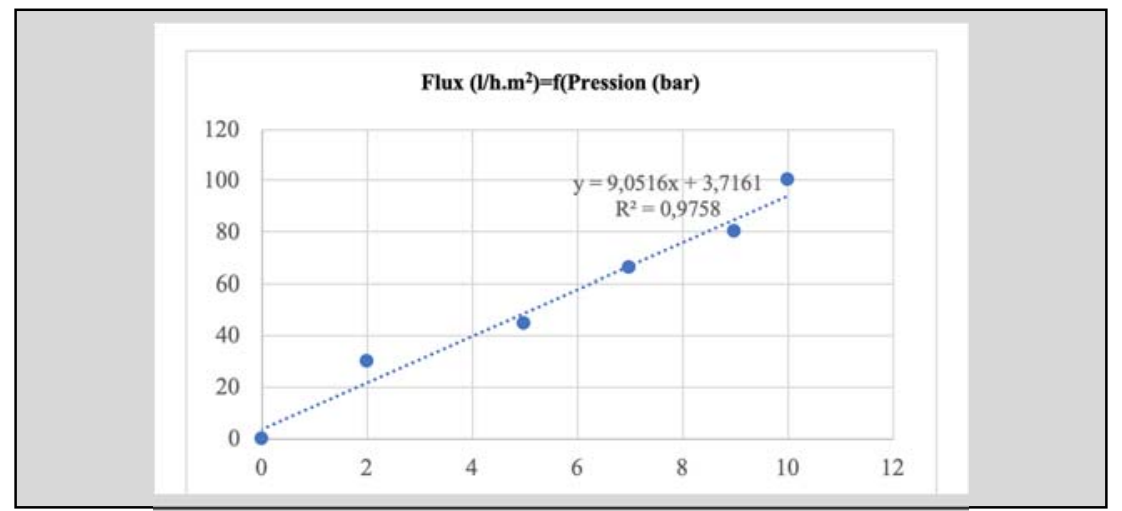

Fig. 5. Water flux as a function of trans-membrane pressure.

\subsubsection{MWCO}

The variation of the rejection rates for increasing molecular weight polymer (PEG) is plotted in fig.6. The cut off of the membrane is approximately $5000 \mathrm{Da}$.

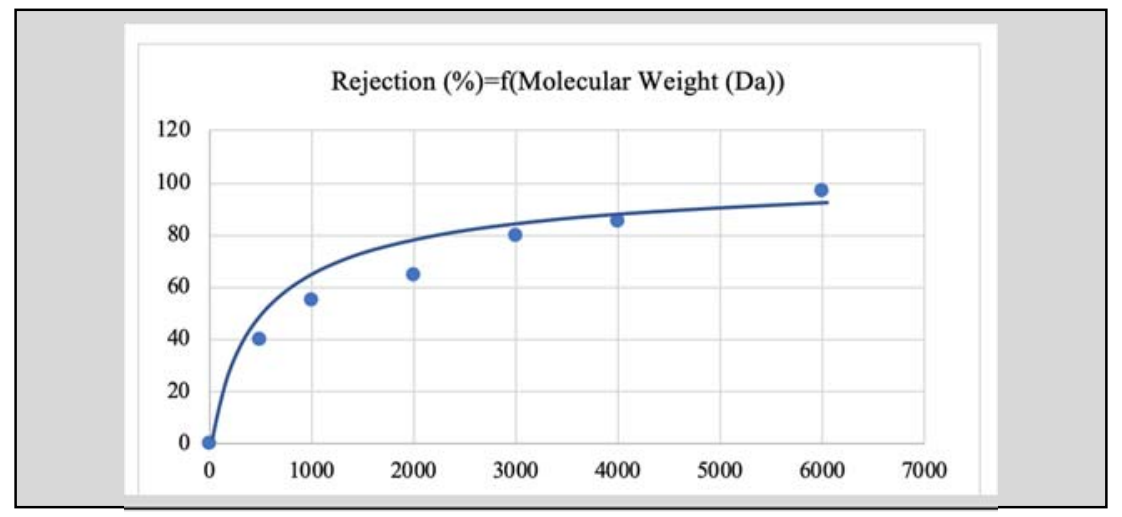

Fig. 6. Rejection rates of PEG at different molecular weight.

\subsection{Salts retention}

\subsubsection{Filtration of $\mathrm{NaCl}, \mathrm{Na}_{2} \mathrm{SO}_{4}, \mathrm{CaCl}_{2}, \mathrm{CaSO}_{4}$}

The performance of developed ultrafiltration membrane in term of rejection towards electrolyte solutions, depend on the electric and steric interaction between the surface of the membrane and the ions. In our case, due to the compared size of the ions and the pore size of the membrane, the main parameters which must be considered are the electric interactions. In the goal to control this, classical electrolyte $\left(\mathrm{NaCl}, \mathrm{Na}_{2} \mathrm{SO}_{4}, \mathrm{CaCl}_{2}, \mathrm{CaSO}_{4}\right)$ solutions were filtered.

$\underline{\mathrm{pH} \text { effect }}$ 
The evolution of the rejection rate for the electrolyte at different $\mathrm{pH}$ value between 2 and 10 are plotted on figure 7 .

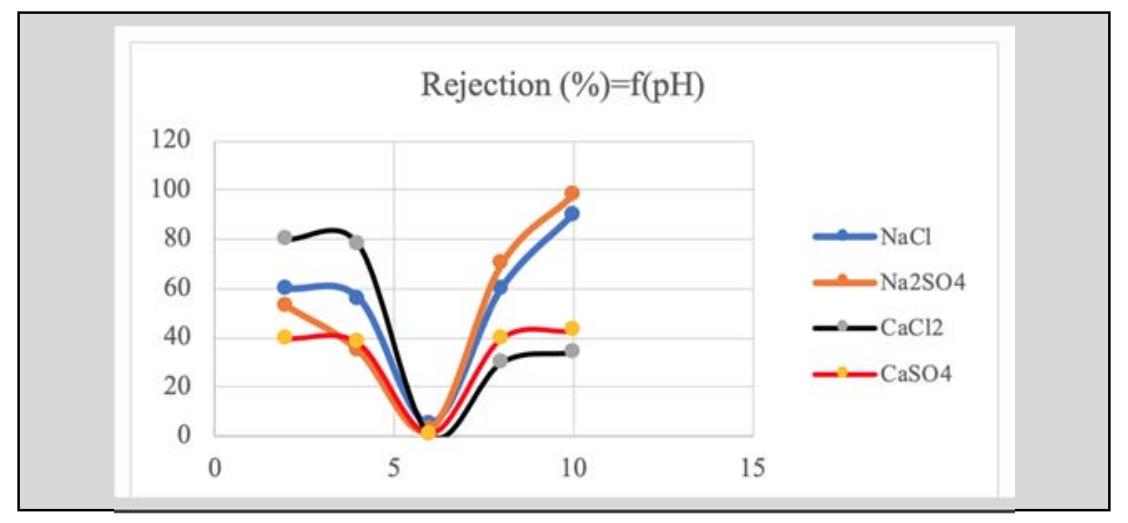

Fig. 7. Salts retention vs. $\mathrm{pH}$ for $\mathrm{NaCl}, \mathrm{Na}_{2} \mathrm{SO}_{4}, \mathrm{CaCl}_{2}, \mathrm{CaSO}_{4}$.

The rejection rate depends strongly on the $\mathrm{pH}$ of the filtered solution.

$\underline{\mathrm{NaCl}, \mathrm{CaCl}_{2}}$ : At $\mathrm{pH}<6$, salt retention can be explained as a result of a positive membrane charge which repels the $\mathrm{Na}^{+}, \mathrm{Ca}^{++}$co-ions [15-17]. In order to satisfy electroneutrality condition, an equivalent number of $\mathrm{Cl}^{-}$counter-ions is retained which results in salt retention.

At $\mathrm{pH}>6$, the membrane exhibits a negative charge, which causes $\mathrm{Cl}^{-}$co-ions repulsion. For $\mathrm{CaCl}_{2}$, At higher $\mathrm{pH}$, the retention reaches a minimal value. To explain these phenomena, we should take account of electrophoretic mobilities of the powder prepared with the $\mathrm{sol}_{\mathrm{TiO}_{2}}$ at the same value $\mathrm{pH}$ [15]. The measurement of electrophoretic mobilities in $\mathrm{CaCl}_{2}$ solution shows when the $\mathrm{pH}$ increases the mobility decrease. That results correlate with the retention of $\mathrm{CaCl}_{2}$

Around $\mathrm{pH}$ 6, the $\mathrm{NaCl}$ retention reaches a low value because the membrane is uncharged. $\mathrm{NaCl}$ is indifferent salt.

$\underline{\mathrm{Na}}_{2} \underline{\mathrm{SO}}_{4}, \mathrm{CaSO}_{4}:$ The rejection of $\mathrm{Na}_{2} \mathrm{SO}_{4}$ is $53 \%$ at $\mathrm{pH} 2$ and then increases until $98 \%$ at higher $\mathrm{pH}$ causes by $\mathrm{SO}_{4}{ }^{2-}$ co-ions repulsion.

For $\mathrm{CaSO}_{4}$, the retention behavior correlates with the membrane charge. At low $\mathrm{pH}, \mathrm{Ca}^{++}$ co-ions repulsion is caused by the positively charged membrane. At high $\mathrm{pH}$, the strongly negatively charged membrane repels the $\mathrm{SO}_{4}{ }^{2-}$ co-ion. Around $\mathrm{pH} 6$, the membrane is uncharged and $\mathrm{CaSO}_{4}$ retention is minimal. [15-18]

The purification efficiency of a developed ceramic membrane depends also on surface interactions between the membrane surface and solutes/solvents. The Elaborate UF membrane have the same behavior of Nanofiltration membrane, they can reject multivalent ions with negligible selectivity toward the monovalent ion, which is the only difference from the reverse osmosis technique.

\section{Conclusion}

This study has shown that a multilayer composite membrane which separation properties are in the ultrafiltration range, could be successfully developed. The tubular ceramic $\mathrm{TiO}_{2}$ membrane studied was found to have a MWCO of 5000 Da and a permeability of 9.01 1/h. $\mathrm{m}^{2}$.bar and have the same behaviour than Nanofiltration membrane. 
The amphoteric of membrane has a strong influence on retention obtained with salts retention and a clear $\mathrm{pH}$ dependency of salts was found.

\section{References}

1. M.K. Purkait, R. Singh, Taylor and Francis Group, LLC, London, NewYork, (2018).

2. C. Das, S. Bose, Taylor and Francis Group, LLC, London, NewYork, (2017).

3. A.J. Burggraaf, L. Cot, Elsevier Science and Technology Series 4, Elsevier, Amsterdam, (1996).

4. A.W. Mohammad, Y.H. Teow, W.L. Ang, Y.T. Chung, D.L. Oatley-Radcliffe, N. Hilal, Desalination, Volume 356, Pages 226-254, (2015).

5. Yanli Ji , Weijie Qian , Yawei Yu , Quanfu An, Lifen Liu, Yong Zhou, Congjie Gao, Chinese Journal of Chemical Engineering, Volume 25, Issue 11, Pages 1639-1652, (2017).

6. Zhensheng Yang, Zheng Sun, Dongsheng Cui, Pingli Li, Zhiying Wang, Chinese Journal of Chemical Engineering, Volume 27, Issue 2, Pages 467-475, ( 2019).

7. RuizhangXu, JiantaoWang, DandanChen, TianyuLiu, ZhuoZheng, FengYang, JinyaoChen, JianKang, Journal of Membrane Science, Volume 595, 117472, (2020).

8. N. El Qacimi, N. El Baraka, N. Saffaj, R. Mamouni, A. Laknifli, S. Alami Younssi, A. Faouzi, H. Zidouh, Desal. Water Treat., 143, Pages 111-117, (2019).

9. A.A. Taleb, N.E. Baraka, N. Saffaj, A. Laknifli, R. Mamouni, A. Fatni, A.E. Hammadi, N.E. Qacimi, E3S Web Conf. 37, 01011, (2018).

10. D. Njoya, M. Hajjaji, D. Njopwouo, Appl. Clay Sci. 65-66, Pages 106-113, (2012).

11. M. Loutou, W. Misrar, M. Koudad, M. Mansori, L.Grase, C. Favotto, Y. Taha, R. Hakkou, Minerals 9, 318, Pages 1-18, (2019).

12. N. Saffaj, M. Persin, S. Alami Younssi, A. Albizane, M. CRETIN \& A. Larbot, Applied Clay Science, 31, Pages 110-119 (2006).

13. N. Saffaj, S. Alami Younssi, M. Persin, M. Cretin, A. Albizane, A. Larbot, Ceramics International 31, Pages 205-210, (2005).

14. N. Saffaj, H. Loukili, S. Alami-Younssi, A. Albizane, M. Persin, Separation and Purification Technology, 45, Pages 36-42, (2005).

15. T. Van Gestel, C Vandecasteele, A. Buekenhoudt, C. Dotremont, J. Luyten, R. Leysen, B. Van.der.Bruggen, G. Maes, J. Membr. Sci, 209, Pages 379-389, (2002).

16. J.Palmeri, P.Blanc, A. Larbot, P.David, J. Membr. Sci. 160, Pages 141-170, (1999).

17. Siyu Wei, Yingbo Chen, Xiaoyu Hu, Chunhao Wang, Xiujing Huang, Dongqing Liu, Yufeng Zhang, Journal of the Taiwan Institute of Chemical Engineers, Volume 112, Pages 169-179, (2020).

18. Yahua Lu ,Zhenping Qin,Naixin Wang, Hongxia Guo,Quanfu An,Yucang Liang, Chinese Journal of Chemical Engineering, Volume 28, Issue 10, Pages 2533-2541, (2020). 